numbness is more marked in the right hand. The paroxysms of shooting pains have lately recurred more frequently, although they have not increased in severity. They chiefly attack the left lower limb. He also complains of a sense of tightness of the abdominal muscles, which to the touch feel tense and rigid. The sensibility of his lower limbs is in the same impaired condition as previously recorded. Their motility has, however, improved considerably; his movements are much less unsteady, he throws his legs much less wildly about, and is not obliged to be constantly keeping watch over them.

(To be continued.)

REPORT OF A CASE OF

\section{LOSS OF A LARGE PORTION OF THE RIGHT PERONEAL NERVE, AND RECOVERY OF PATIENT WITHOUT AMPUTATION.}

\section{By WM. STUART-MUNRO, M.D., M.R.C.S.,} SURGEON TO TEE WEST HARTLEPOOL IRON WORKS.

WM. G- aged thirty-five, a spare but healthy and sober man, on the 26th of October last, got his right leg entangled in the planing machine of the iron-rolling mill here, a pin of the machinery entering the right popliteal space, and tearing away the skin and fascia from that region, as well as about two inches of the peroneal nerve from the head of the fibula downwards. The sciatic nerve, dividing into the peroneal and posterior tibial, was also exposed, but no injury was done to the latter or any of the bloodvessels, though the knee-joint was severely bruised and the man complained of great pain. After the accident he was placed at once on strict antiphlogistic treatment and diet, and poultices were applied to the seat of injury.

Nov. 6th.-All went on satisfactorily until to-day. Now, however, he complains of severe pain in the knee-joint, which is much swollen. Ordered six leeches to be applied to each side of the joint, and to take a smart purge.

20th. - Very little pain since last report until to-day, when it became so severe in the course of the exposed portion of the peroneal nerve that about two inches had to be removed, after which he got almost immediate relief. The wound has now become considerably smaller, but there is a profuse discharge of thick pus from it.

25th. - The pain has not troubled him much since last report, but the swelling of the joint is still considerable, and the discharge of matter is still increasing much in quantity. There is a small slough coming away from over the posterior tibial nerve, and his general health is far from good. He has now slight œedema at the ankle. The heat of the foot is natural, but the sensation of the parts supplied by the peroneal nerve is gone, and that of those supplied by the posterior tibial is greatly impaired. He is now placed upon more generous diet, with wine and quinine, and turpentine liniment dressing applied to the sore.

30th. - Since last report the discharge has been increasing in quantity; his strength is daily giving way under it. Pulse 96 , small, soft, and jerking; left side of the tongue covered with a thick yellow fur; patient's mind wanders during the night. Amputation is now strongly advised, but the patient and his friends will not hear of it.

Dec. 3rd. - Tongue still very foul, but bowels regular. He is extremely weak, and has a very anxious countenance. The discharge has not increased since last report. The quantity of wine to be increased, and the quinine (which disordered the stomach) to be changed for tincture of muriate of iron.

15th.-Tongue now very clean; discharge moderating; the patient is gaining strength; wound now about the size of a shilling. Placed him on cod-liver oil.

18th.-Stomach unable to retain the oil; to have instead syrup of iodide of iron. Wound and round about the kneejoint to be dressed with turpentine liniment, one ounce, and biniodide of mercury, six grains.

21st.-Discharge from wound much abated. Have now increased the wine to a pint daily, and taken him out of bed for a little; but he is still very weak, though almost free from pain.

24 th. - When out of bed yesterday, about an ounce of arterial blood came from wound. Changed the dressing on it to oxideof-zinc ointment, but continued the other dressing around the leg. To-day feels some sensation all over the foot, but cannot make the slightest use of the extensors.

26th.-A distinct fluctuation can be detected on the inside of the lower third of the thigh, over the course of the femoral vessels ; and on pressing there, a quantity of thick matter escapes at the wound, which is now healing rapidly. Introduced a drainage-tube, and passed a tight bandage round the limb.

30th. - Cannot bear the pain which the tube creates any longer, so had to discontinue its use, as also that of the biniodide-of-mercury ointment. Have to-day applied a leatherlined split splint to the outside of the thigh, and a thick compress over the entire sinus, binding both firmly together with two straps encircling the limb.

Jan. 2nd. - Very little discharge since last report, and what comes now is like synovia. Matter can, however, be detected in its original seat, which is given free vent by incision.

14th. - All is now completely healed, and there is no sign of the presence of any matter. His health is much improved, and the knee-joint is getting smaller, though very little motion now remains in it.

April 4th. - He has gradually improved since last report; is now able to walk well with the use of a stick; has lost almost all use of the joint, and entirely that of the extensors, but has ingeniously contrived a spring as a substitute for the latter His foot and ankle are swelled considerably by bed-time after walking about during the day; but he is free from pain, and feels strong enough to intend commencing his work-that of a brass-turner-next week.

Strath Cottage, April, 1865

\section{ON DISLOCATION OF THE KNEE.}

\section{BY WM. NORRIS, M.D.}

THE late Mr. Samuel Cooper in his valuable Dictionary says that complete dislocations of the knee are exceedingly rare; because the articular surface of the condyles of the femur is so extensive that the tibia cannot be entirely removed from it without a prodigious laceration of the ligaments, tendons, and all the rest of the soft parts. And Boyer seems to question the possibility of such an accident, which makes me desirous to publish the two following cases.

A young man was employed near an immense wheel, which in its revolutions came within a foot of the ground, and, while stooping, his clothes became entangled in it, and he was seen to be carried round many times, and doubled up each time as his body came to the earth, before the wheel could be stopped. I saw him with $\mathrm{Mr}$. Reeves, of Kinver, about a quarter of an hour after the accident, and found him bleeding at the mouth, with his face blue, and perfectly senseless; the tibia was forced from the joint, and thrown behind the condyles of the femur into the ham. The external integuments were not torn, but the ligamentum patellæ was ruptured, the fibula fractured, and many of the ribs were broken into splinters, and must have been driven into the lungs, producing the hwomorrhage from the mouth. The radius and ulna of one arm were fractured, and the ends of both bones were sticking out of the integuments more than an inch; and in his agonies he was twirling this broken arm round and round, till death closed his miserable existence, about half an hour after the accident, which took place at the Hyde Iron Works, near Stourbridge.

The following case of compound dislocation of the knee joint is, I am inclined to believe, almost without a parallel:A young man got entangled in the large wheel of a steam engine, and was carried swiftly round and doubled up many times before the wheel could be stopped, which caused compound dislocation of the knee-joint. The os femoris protruded through the lacerated integuments four inches; and, singular to state, the bone was perfectly free from ligaments and muscles, looking as if it had been carefully cleansed; even the cartilages were removed from the bone-I suppose from the violent and repeated friction against the hard ground; the periosteum was also detached in several places, and the tibia was forced into the ham. Dr. Campbell performed amputation about the middle part of the thigh, and the man appeared to be going on well for nearly three weeks, when probably suppurative inflammation came on in the lungs; for he had spitting of blood congh, \&c., and in a few days died. 
This case occurred in the practice of my friend Dr. Campbell, of this town, at Mr. Wood's iron manufactory near here; and $I$ am indebted to him and his friend Mr. Stubbs for all par. ticulars.

When we reflect upon the sudden and immense power of these large wheels, we cannot wonder at finding simple or compound dislocations taking place in one of the strongest joints of the body. A compound dislocation of the knee must produce so great a shock to the system, that I should think very few would recover from such an accident.

In this town and neighbourhood we have numerous ironworks with the most complicated and powerful machinery, and the most awful accidents occasionally occur. In some manufactories large shears are used, which cut through thick bars of iron with perfect ease. I have known two cases where men hare been sleeping near them, and their heads have been serered from their bodies.

I have seen a strong man who got entangled in powerful machinery, and the os femoris was torn out of the hip-joint, hanging only by a few muscles; these were divided and the limb removed, and the man had a good recovery. I have seen him walking about tolerably well.

Stourbridge, April, 1865.

ON A CASE OF

\section{COMPOUND FRACTURE OF THE SKULL.} TREPHINING; RECOVERY.

\section{BY HERBERT EVERITT, M.R.C.S.}

ED. W-, aged fourteen, on the 19th October, 1864, fell from a ship's mast to the deck, a distance of about twenty feet, his head coming in contact with a piece of projecting iron. I saw him almost immediately, and found upon the summit of the head a large wound, with less important ones upon other parts of the scalp. Upon examining the larger wound, it was found to communicate with a depressed fracture. The lad was drowsy, but answered questions when loudly spoken to; he had been perfectly insensible from concussion, but had rallied from that state. Pulse 70, small and feeble; pupils contracted evenly; no paralysis ; body cold.

I determined to trephine, and, with the assistance of $\mathrm{Mr}$. Long, proceeded to perform the operation. On enlarging the wound, the fracture was found to be situate in the middle line, at the junction of the parietal with the frontal bones. A triangular portion of bone, about one inch in its greatest length and breadth, was found firmly depressed, so that the outer table of the depressed portion was fixed against the inner table of the uninjured bone, the triangle being attached at its base. By removing a small button of bone with the trephine I was enabled to elevate this; but finding that the inner table was further fractured and depressed, I used a small Hey's saw to remove an angle of bone, which admitted of the whole being elevated to its proper level. The longitudinal sinus was seen through the dura mater, which was uninjured. Hæmorrhage was inconsiderable; the wound was closed with sutures and dressed with cold water; and the whole scalp, which had been shaved, was covered with cold wet cloths.

The boy was quiet during the operation, and after it answered questions readily, even volunteering remarks. In the evening he complained of pain in the back of the neck, and hunger.

20th. - Was sick in the morning, but immediately afterwards complained of hunger; pulse 60 ; head kept wet and cool ; no pain.

21st.-Sutures removed; parts of wound united; allowed tea and arrowroot; bowels acted upon with calomel and jalap.

From this time the boy made a rapid recovery, his only complaint being hunger. Once, from an indiscretion in diet, he beeame restless, and complained of pain at the seat of injury, but a full dose of castor oil relieved the symptoms. The boy is now well, and working on board ship.

I am induced to report the above case as being evidence in favour of immediate operative interference in compound fracture of the skull with depression, and as opposed to the opinion of other medical men in this neighbourhood, who advocate the waiting for more advanced symptoms of depression than existed in this case.

Wells, Norfolk, April 24th, 1865̃.

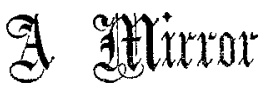

OF THE PRACTICE OF

\section{MEDICINE AND SURGERY}

IN THE

\section{HOSPITALS OF LONDON.}

Nulla autem est alia pro certo noscendi via, nisi quamplurimas et morborum et dissectionum historias, tum aliorum, tum proprias collectas habere, et inter se comparare,-Morgakn De Sed. et Caus. Morb., lib. iv. Procmium.

\section{CHARING-CROSS HOSPITAL.}

DISEASE OF THE LEFT UPPER JAW-BONE, ORIGINATING PRIMARILY IN A BLOW FROM THE FIST ; SUCCESSFUL REMOVAL OF THE ENTIRE BONE.

(Under the care of Mr. CANToN.)

Perhaps there is not a more formidable operation in surgery than the removal of the upper jaw, more especially as producing a startling effect on the spectator who may witness it for the first time in his career. Yet it is not one so fatal in its results as many other surgical operations; indeed, the records of hospital practice rather point to the pretty general recovery from the immediate effects of the operation, whatever the ultimate results may prove to be. We have been favoured by Mr. W. Travers, the resident medical officer of the hospital, with the following notes of a case of much interest, wherein disease showed itself at the side of the nose from the blow of a fist. This was removed on two occasions, but still with a recurrence involving the left upper jaw, which now attained such dimensions as not only to affect important parts, but seriously to threaten life, requiring the ablation of the entire bone to hold out a chance of a good and satisfactory cure. This was done by Mr. Canton with the results described in the details of the case; but it fully bears out the value of the maxim to remove an entire bone, and not a portion of it only, when once its structure becomes involved, as was the fact in the present instance. The patient appears to have made an excellent recovery, with the probability of future immunity from the disease.

M. F-, aged thirty-five, a native of Wainfleet, though for the past five years residing at Malta, the wife of a soldier, was admitted into the Victoria ward on August 29th, 1864, with a tumour in the left superior maxilla. She stated that about five and a half years previously, some short time before leaving England for Malta, she received a violent blow on the side of the nose from her husband's fist, which rendered her insensible; and soon after reaching Malta she noticed a small lump on the left side of her nose. This gradually enlarged, until at the end of a twelvemonth it had attained such dimensions as to be very inconvenient and unsightly; and it was removed by the regimental surgeon. The wound healed rapidly; but after the lapse of some months it again made its appearance, and gradually increased in size until about fourteen months since, when it was once more removed by operation. The wound was nearly closed, when the disease for a third time made its appearance; and as it now seemed rapidly to increase, the patient came to London, and placed herself under Mr. Canton's care. Her general health was, and had been, very good; complexion dark and somewhat sallow. None of her relations have suffered from any similar disease. The tumour appeared about the size of a turkey's egg, extending the entire length of the left side of the nose, bulging into the nostril, and reaching across the cheek so as to overlap the malar bone of the same side. By placing the finger behind the soft palate, an elastic mass could be felt protruding into the pharynx. Externally it felt firm and semi-elastic, but non-fluctuating. There was an occasional discharge of blood and dark grumous fluid from the left nostril.

On the 8th of October Mr. Canton removed the entire superior maxilla of the affected side, making the usual incisions. This was effected without much difficulty after separating the osseous attachments with bone forceps. But little hæmorrhage occurred during the operation, and no vessel required ligature. The whole of the disease came away with the maxilla. The surface of the wound looked normal. The edges of the 